\title{
Differential Contribution of Hippocampal Subfields to Components of Associative Taste Learning
}

\author{
Adaikkan Chinnakkaruppan, ${ }^{1}$ Marie E. Wintzer, ${ }^{3}$ Thomas J. McHugh, ${ }^{3 \star}$ and Kobi Rosenblum ${ }^{1,2 \star}$ \\ ${ }^{1}$ Sagol Department of Neurobiology and ${ }^{2}$ Center for Gene Manipulation in the Brain, University of Haifa, Haifa 31905, Israel, and ${ }^{3}$ Laboratory for Circuit \\ and Behavioral Physiology, RIKEN Brain Science Institute, Saitama, Japan 351-0198
}

\begin{abstract}
The ability to associate the consumption of a taste with its positive or negative consequences is fundamental to survival and influences the behavior of species ranging from invertebrate to human. As a result, for both research and clinical reasons, there has been a great effort to understand the neuronal circuits, as well as the cellular and molecular mechanisms, underlying taste learning. From a neuroanatomical perspective, the contributions of the cortex and amygdala are well documented; however, the literature is riddled with conflicting results regarding the role of the hippocampus in different facets of taste learning. Here, we use conditional genetics in mice to block NMDA receptor-dependent plasticity individually in each of the three major hippocampal subfields, CA1, CA3, and the dentate gyrus, via deletion of the NR1 subunit. Across the CA1, CA3, and dentate gyrus NR1 knock-out lines, we uncover a pattern of differential deficits that establish the dispensability of hippocampal plasticity in incidental taste learning, the requirement of CA1 plasticity for associative taste learning, and a specific requirement for plasticity in the dentate gyrus when there is a long temporal gap between the taste and its outcome. Together, these data establish that the hippocampus is involved in associative taste learning and suggest an episodic component to this type of memory.
\end{abstract}

Key words: association learning; hippocampus; incidental learning; NMDA receptor; plasticity; taste learning

\section{Introduction}

Associative taste learning, in which animals, including humans, associate a specific tastant consumed with its postingestive consequences, nausea or safety, is robust and long lasting. This adaptive learning can also prove detrimental, as evidenced by the frequency at which patients receiving chemotherapy struggle with the powerful association between post-treatment sickness and the taste of pretreatment meals (for review, see Reilly and Bornovalova, 2005). In the last 60 years, many of the neural circuits and structures underlying this type of learning have been identified. The gustatory cortex, the amygdala, and the parabrachial nucleus of the pons are all critical; however, the role of the hippocampus in taste learning and memory is still subject to debate (Rosenblum et al., 1993; Yamamoto et al., 1995; Yefet et al., 2006; Ding et al., 2008; Elkobi et al., 2008; Barki-Harrington et al., 2009; GalBen-Ari and Rosenblum, 2012; Gildish et al., 2012; Piette et al., 2012; Inberg et al., 2013; Stern et al., 2013). While biochemical analyses observe novel taste learning-dependent changes in

\footnotetext{
Received March 10, 2014; revised June 6, 2014; accepted June 25, 2014.

Author contributions: A.C., T.J.M., and K.R. designed research; A.C., M.E.W., and T.J.M. performed research; A.C., M.E.W., and T.J.M. analyzed data; A.C., T.J.M., and K.R. wrote the paper.

This work was supported by European Union Seventh Framework Program EUROSPIN (Contract HEALTH-F22009-241498) and the German-Israeli Foundation DIP (R03971/1-1; K.R.) and by the RIKEN Brain Science Institute (T.J.M.). We thank members of the laboratory of K.R. and T.J.M. for their support and encouragement.

*T.J.M. and K.R. jointly directed this work.

Correspondence should be addressed to Thomas J. McHugh, RIKEN Brain Science Institute, Laboratory for Circuit and Behavioral Physiology, 2-1 Hirosawa, Wako-shi, Saitama, Japan, 351-0198. E-mail: tjmchugh@brain.riken.jp DOI:10.1523/JNEUROSCI.0956-14.2014

Copyright $\odot 2014$ the authors $\quad 0270-6474 / 14 / 3411007-09 \$ 15.00 / 0$
}

protein expression and phosphorylation in the hippocampus, behavioral studies have reported a wide array of phenotypes following hippocampal damage. Previous studies have reported impaired, normal, or even enhanced conditioned taste aversion (CTA), an associative form of taste learning and memory, following pharmacologically mediated inactivation or hippocampal lesions (Murphy and Brown, 1974; Miller et al., 1975, 1986; Bakner et al., 1991; Reilly et al., 1993; Purves et al., 1995; Yamamoto et al., 1995; Stone et al., 2005; De la Cruz et al., 2008; Ding et al., 2008; Koh et al., 2009; GarciaDelatorre et al., 2010). However, despite these inconsistencies, current literature continues to suggest that taste learning and memory is considered to be "hippocampus-independent," even in its associative form (Ding et al., 2008; Ballarini et al., 2009).

To reconcile these differences and better understand the hippocampal contribution to taste learning, we used a conditional genetic approach to allow the function of specific subregions of the hippocampus to be spatially and temporally regulated. Previous behavioral and electrophysiological studies using CA1-, CA3-, and DG-specific NMDAR subunit NR1 knock-out mice (CA1-NR1 KO; CA3-NR1 KO; DG-NR1 KO; Tsien et al., 1996; Nakazawa et al., 2002; McHugh et al., 2007) have delineated the distinct roles of the different regions of the hippocampus in spatial and contextual learning (McHugh et al., 1996, 2007; Tsien et al., 1996; Nakazawa et al., 2002). Using these well characterized transgenic lines as variants of hippocampal circuit function, we investigated the role of the hippocampus in several forms and stages of taste learning and memory. 


\section{Materials and Methods}

Mice. CA1-NR1 (Tg(Camk2a-cre)T29-1Stl; Grin1tm2Stl/Grin1tm2Stl mouse; Research Resource Identifier (RRID): MGI_MGI:3581524), CA3-NR1 (C57BL/6-Tg(Grik4-cre)G32-4Stl/J mouse; RRID: IMSR_JAX:006474 crossed with Grin1tm2Stl/Grin1tm2Stl mouse; RRID: MGI_MGI:2175051), and DG-NR1 KO (Grin1tm2Stl/Grin1tm2Stl; $\mathrm{Tg}$ (Pomc-cre)1Stl mouse; RRID: MGI_MGI:4362041) mice were bred and genotyped as previously described (Tsien et al., 1996; Nakazawa et al., 2002; McHugh et al., 2007). Male KO mice from each line were used for experiments at the following ages: CA1-NR1 KO, 6-12 weeks; CA3NR1 KO, 18-25 weeks; DG-NR1 KO, 20-40 weeks. Male flNR1 homozygous littermates from all three lines were used as age-matched controls (Grin1tm2Stl/Grin1tm2Stl mouse; RRID: MGI_MGI: 2175051). c-fos promoter activity was assessed using mice derived from the TetTag mice (B6;DBA-Tg(Fos-tTA,Fos-EGFP)1Mmay/J mouse; RRID: IMSR_JAX:008344; Reijmers et al., 2007) that carried the c-Fos promoter driving a $2 \mathrm{~h}$ half-life EGFP (c-fos-shEGFP) and were bred and genotyped as previously described. Arc expression experiments were performed in C57BL/6 male mice bred in-house (12-16 weeks old). All mice were bred and the experiments were performed at the RIKEN Brain Science Institute (Wako-Shi, Saitama, Japan). They were maintained in groups, in a humidity- and temperature-controlled environment, under a $12 \mathrm{~h}$ light/dark cycle (lights on at 8:00 A.M.) with ad libitum access to food and water. Mice were individually housed before the start of the experiments. Experiments were conducted during the light phase. Efforts were taken to minimize the number of mice used. All the experiments were performed in the home cages of mice by an experimenter blind to the genotypes. All protocols were approved by the RIKEN Institutional Animal Care and Use Committee.

Conditioned taste aversion. Mice were habituated to get their daily water ration once a day for $20 \mathrm{~min}$ from two pipettes, each containing 5 $\mathrm{ml}$ of water, for $3 \mathrm{~d}$. On the fourth (conditioning) day, they were allowed to drink $0.5 \%$ sodium saccharin (Sigma) solution from similar pipettes for $20 \mathrm{~min}$, and $0,40,100$, or $220 \mathrm{~min}$ later were injected with lithium chloride [LiCl, a gastric malaise inducer; $0.14 \mathrm{~m} ; 2 \%$ body weight (b.w.) ] for immediate, $1 \mathrm{~h}, 2 \mathrm{~h}$, or $4 \mathrm{~h}$ intertime interval (ITI)-CTA training, respectively. They were given $20 \mathrm{~min}$ access to water on days 5 and 6 . On day 7 , mice were subjected to a multiple-choice test situation involving two pipettes with $5 \mathrm{ml}$ each of conditioned taste solution (saccharin) and two with $5 \mathrm{ml}$ each of water. The order of the pipettes was counterbalanced and the volume of fluid consumed from each tube was recorded. The behavioral data are expressed in terms of aversion index- the volume of water consumed divided by the total fluid consumed ( $\mathrm{ml}$ water/ml water plus $\mathrm{ml}$ taste).

For reinstatement, $8 \mathrm{~d}$ after the last extinction test, the mice were injected with $\mathrm{LiCl}(0.14 \mathrm{M} ; 2 \%$ b.w.) and $24 \mathrm{~h}$ later were subjected to the same multiple-choice tests administered on day 7.

Latent inhibition. The mice were trained for $3 \mathrm{~d}$ to get their daily water ration once a day for $20 \mathrm{~min}$ from two pipettes, each containing $5 \mathrm{ml}$ of water. On the preexposure day, the mice were exposed to sodium saccharin solutions for $20 \mathrm{~min}$, in two $5 \mathrm{ml}$ pipettes. The next day, mice were again allowed to get their daily water ration for $20 \mathrm{~min}$. On the conditioning day, they were again allowed to drink the saccharin solution from similar pipettes for $20 \mathrm{~min}$, and $40 \mathrm{~min}$ later were injected with $\mathrm{LiCl}(0.14 \mathrm{M} ; 2 \%$ b.w.). Testing and data analysis were conducted in a manner similar to CTA.

Taste preference, attenuation of neophobia, and long-term safe taste memory. Mice were trained to drink from pipettes for $20 \mathrm{~min}$ per day for $2 \mathrm{~d}$, and on the third day, they underwent multiple-choice tests involving two pipettes with $5 \mathrm{ml}$ each of novel sweet $(0.5 \%$ sodium saccharin) taste solution or bitter $(0.04 \%$ quinine $)$ taste solution and two pipettes with 5 $\mathrm{ml}$ each of water. For attenuation of taste neophobia, the mice underwent similar multiple-choice tests for the next $2 \mathrm{~d}$. Mice were given water $a d$ libitum for the next $14 \mathrm{~d}$, and on the 15th day they were water restricted. They underwent multiple-choice tests on the 16th day to test long-term safe taste memory. The behavioral data are expressed in terms of preference index ( $\mathrm{ml}$ taste $/ \mathrm{ml}$ water plus $\mathrm{ml}$ taste).

LiCl-induced gut pain. An automated tracking system, ANY-maze (Stoelting) was used to see if there was any difference in the exploratory behavior following $\mathrm{LiCl}$ injection, to indirectly measure the $\mathrm{LiCl}$-induced gut pain sensation (Ding et al., 2008). A standard rodent housing cage was used as the chamber (floor area of $140 \mathrm{sq}$ in; 11.25 inches wide $\times 15.5$ inches deep $\times 7.6$ inches high). The mice were placed in the chamber, and $10 \mathrm{~min}$ after the initial exploration, they were injected with $0.14 \mathrm{M}$ $\mathrm{LiCl}, 2 \%$ b.w. They were monitored using a CCD camera connected to the ANY-maze program. The length they traveled was transferred to MS Excel and analyzed.

In situ hybridization. For taste learning and tissue preparation, mice (C57BL/6J) were trained to drink from pipettes for $10 \mathrm{~min}$ per day for $3 \mathrm{~d}$, and on the fourth day they received either water (control) or novel taste (saccharin) for $10 \mathrm{~min}$. They were killed 3-5 min later. Brains were flash frozen and transferred to $-80^{\circ} \mathrm{C}$ temperature until further processed.

Fluorescence in situ hybridization and cell counting for the immediate early gene Arc were performed according to a previously described protocol (Wintzer et al., 2014).

To verify the restriction of the NR1 gene deletion in the CA1-NR1 KO, CA3-NR1 KO, and DG-NR1 KO mice, we conducted in situ hybridization as previously described on two mice of each genotype at the same ages used for behavioral testing (Wintzer et al., 2014) using an NR1 probe (FANTOM clone 4732488C07) labeled with fluorescein. Fluorescent images $(5 \times)$ of the resulting sections were collected on a Leica DM6000B epifluorescence microscope such that each contained one hemisphere of the entire dorsal hippocampus and overlaying cortex. An experimenter blind to the genotype of the animals processed the images for quantification ( $n=3-4$ per mouse) by first converting the color image to grayscale and subsequently measuring pixel density in four regions: (1) layer IV of the cortex, (2) CA1 and (3) CA3 pyramidal cell layers, and (4) the DG granule cell layer. Two independent measurements were made in each region in each section and averaged. All hippocampal regional values were then normalized by dividing the average cortical density, resulting in a single normalized value for each subregion in each section.

$c$-fos promoter activity. c-fos-shEFGP mice were trained to drink from pipettes for $10 \mathrm{~min}$ per day for $3 \mathrm{~d}$, and on the fourth day they received either water (control) or novel taste (saccharin) for $10 \mathrm{~min}$. Two hours later, they were perfused with $4 \%$ paraformaldehyde, and the brain was postfixed with the same fixative for $72 \mathrm{~h}$ at $4^{\circ} \mathrm{C}$. Brain slices $(50 \mu \mathrm{m})$ were washed three times with PBS, mounted on slides, and coverslipped with Vectashield mounting medium containing DAPI (Vector Laboratories) for nuclear counterstaining. Quantification of the EGFP signal was performed using ImageJ software by an experimenter blind to the treatment groups.

Statistical analysis. All grouped data are expressed as means \pm SEM. Data analysis was performed with SPSS version 19 or GraphPad Prism (version 5.04 for Windows). Statistical analyses were conducted using two-tailed paired or independent-sample Student's $t$ test, Pearson's correlation, one-way ANOVA, two-way ANOVA, multivariate ANOVA (MANOVA), and repeated-measures ANOVA, as appropriate, with Dunnett's post hoc test (when one group served as a control) or Bonferroni's post hoc test. Significance for all analyses was defined as $p<0.05$.

\section{Results}

To examine the role of hippocampal plasticity in taste learning, we first confirmed the layer-specific deletion of NR1 (Grin1) gene by in situ hybridization in the conditional knock-out mice lines (Fig. 1A). Consistent with previous reports (Tsien et al., 1996; Nakazawa et al., 2002; McHugh et al., 2007), CA1-, CA3-, and DG-NR1 KOs showed clear deletion of NR1 gene restricted to the appropriate layer of the hippocampus with a faint in situ signal remaining in the deleted subfields due to the expression of the NR1 message in interneurons located in the cell body layer (Fig. $1 B$; two-way ANOVA: NR1 KO lines $\times$ NR1 expression in hippocampus subregion interaction, $F_{(6,63)}=42.57, p<0.0001$; Bonferroni post hoc test, CA1-NR1 KOs: CA1 $p<0.0001$, CA3 $p>0.05, \mathrm{DG} p>0.05$; CA3-NR1 KOs: CA1 $p>0.05, \mathrm{CA} 3 p<$ 0.0001, DG $p>0.05$; DG-NR1 KOs: CA1 $p>0.05$, CA3 $p>0.05$, 
A

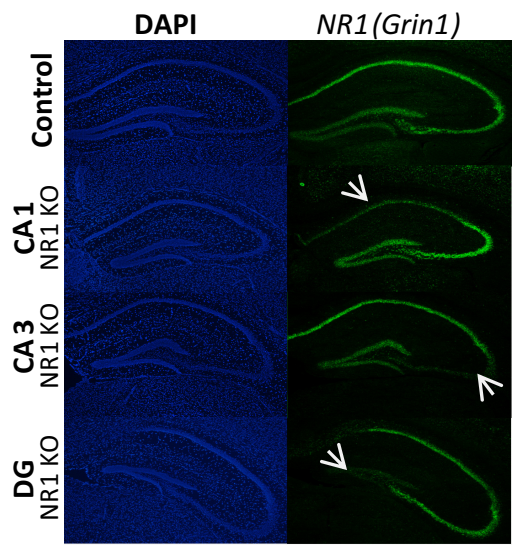

B

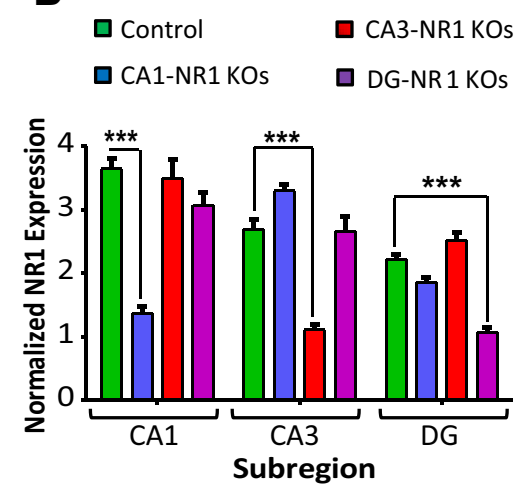

D

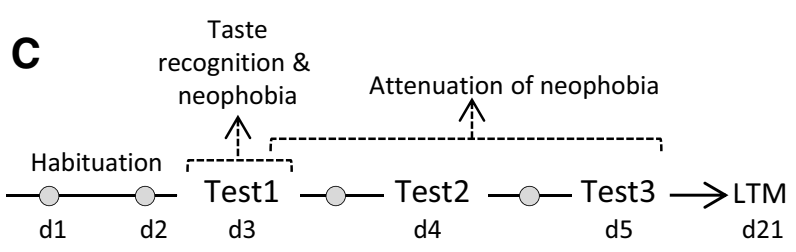

E

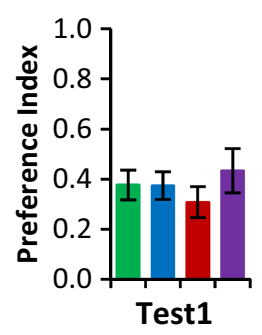

$\sim-$ Control
$\mathbf{F}$

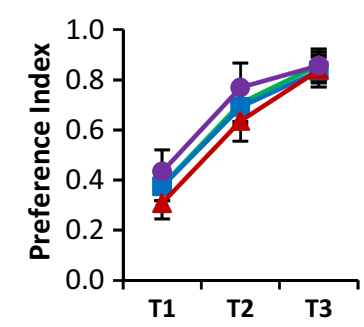

$\sim$ CA3-NR1 KOS

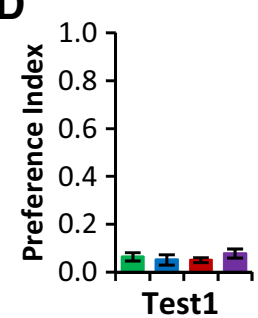

G

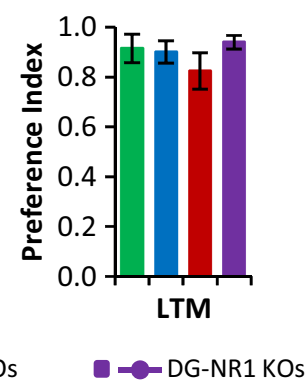

Figure 1. Incidental taste learning, attenuation of taste neophobia, and long-term safe taste memory formation do not require hippocampal plasticity. $\boldsymbol{A}$, Subregion-specific NMDA receptor subunit NR1 deletion (indicated by arrow) revealed by in situ hybridization. DAPI (left) and NR1 (right) probe labeling of hippocampi of control, CA1-, CA3-, and DG-NR1 K0 mice. B, CA1-, CA3-, and DG-NR1 KOs showed clear deletion of NR1 gene restricted to the appropriate layer of the hippocampus. $C$, Outline of the behavioral procedure. Following habituation to drink from pipettes for $20 \mathrm{~min}$ per day for $2 \mathrm{~d}$, the mice were tested for taste recognition and neophobia (Test 1), attenuation of taste neophobia (Tests 1, 2, and 3) and long-term memory for the familiarized taste. D, CA1-, CA3-, and DG-NR1 KOs demonstrated normal unpalatable bitter (quinine) taste recognition. $\boldsymbol{E}$, Separate cohorts of CA1-, CA3-, and DG-NR1 K0 mice also showed a normal neophobia to palatable novel sweet (saccharin) taste. F, G, CA1-, CA3-, and DG-NR1KOs also exhibited normal attenuation of taste neophobia (saccharin; $\boldsymbol{F}$ ) and long-term taste memory storage (saccharin; $\boldsymbol{G}$ ).

DG $p<0.0001 ; 2$ mice for each genotype, $n=6-7$ images per group).

\section{Incidental taste learning}

Mice spontaneously exhibit taste neophobia, the reluctance to consume a novel taste due to a lack of knowledge regarding its postingestive consequences. This behavior is a vitally important feeding activity, as it increases the probability of survival by promoting avoidance of novel, and perhaps fatal, tastes (Reilly and Bornovalova, 2005). As outlined in Figure $1 C$, we conducted a series of behavioral experiments to test whether NMDA receptordependent hippocampal plasticity is required for taste neophobia. CA1-NR1, CA3-NR1, and DG-NR1 KO mice all exhibited normal taste neophobia to both an unpalatable bitter taste (quinine; Fig. $1 D$; control mice, $n=7$; CA1-NR1 KOs, $n=6$; CA3-
NR1 KOs, $n=7$; DG-NR1 KOs, $n=7$; one-way ANOVA, $F_{(3,24)}=0.887, p=$ 0.462 ) and a palatable sweet taste (saccharin; Fig. $1 E ; n=5$ mice per group, oneway ANOVA, $\left.F_{(3,16)}=0.592, p=0.629\right)$. Taste neophobia is modified by experience; the sampling of a taste stimulus without aversive consequences leads to an establishment of a "safe taste" memory trace which favors an increase in the consumption of the taste when encountered in the future, a phenomenon called attenuation of neophobia. Therefore, we subjected CA1-NR1, CA3-NR1, and DG-NR1 KOs to experimental attenuation of neophobia tests and again found their behavior no different from controls (Fig. 1F; mixed-model repeated-measures ANOVA: there was a main effect of test, $F_{(2,15)}=123.514, p<0.0001$, but there was no interaction between tests and genotypes, $\left.F_{(6,32)}=0.297, p=0.934\right)$. Moreover, CA1-, CA3-, and DG-NR1 KOs also exhibited normal safe taste memory when tested $16 \mathrm{~d}$ later (Fig. $1 G$; $n=5$ mice per group, one-way ANOVA, $\left.F_{(3,16)}=0.901, p=0.463\right)$, indicating that hippocampal plasticity is not critical for the acquisition or consolidation of incidental taste memory.

To further explore hippocampal activation during sensory learning, we examined whether incidental taste learning leads to the activation of the immediate early genes $A r c$ and c-fos in the individual subfields (Fig. 2A,C). Consistent with our behavioral results, we did not find any significant difference in nuclear Arc mRNA expression (Fig. 2B) in the CA1 or CA3 between the water and novel taste learning groups ( $n=11$ mice per group, unpaired $t$ test; CA1, $\mathrm{t}_{20}=-0.102, p=0.919 ; \mathrm{CA} 3$, $\left.\mathrm{t}_{20}=0.672, p=0.509\right)$. We did not include the DG subregion in this analysis due to the sparse signal in the DG (2-3\% of cells express arc), which makes statistically significant observations difficult and prone to noise. To examine DG activation, we used a complementary approach, a transgenic mouse expressing EGFP under the control of the c-Fos promoter (Reijmers et al., 2007). Again, we found no significant difference in c-Fos promoter-driven EGFP expression (Fig. 2D; Koh and Bernstein, 2005) in the CA3 or DG subregions of hippocampi of mice exposed to water and those exposed to a novel taste (unpaired $t$ test; CA3, $t_{6}=0.919, p=0.394$; DG, $t_{6}=-0.971, p=$ 0.369).

\section{Associative taste learning and memory}

We next addressed the role of the hippocampus in associative taste learning and memory using the standard CTA paradigm (Fig. 3A). In CTA, a novel and palatable taste (conditioned stimulus, CS) becomes aversive following its association with gastric discomfort (unconditioned stimulus, US). The control group 
in these experiments included agematched male flNR1 homozygous littermates from all three mutant lines; therefore, we first examined whether there was any difference in CTA strength between the three types of littermates and found no significant effect $(n=10 \mathrm{flNR} 1$ control littermates from each of the three lines; one-way ANOVA, $F_{(2,27)}=1.467$, $p=0.248)$ and thus combined these results to represent a single control group. Compared with these controls, we observed a significant attenuation of CTA memory in CA1-NR1 KO mice, but not in the CA3-NR1 or DG- NR1 KO lines (Fig. $3 B$; controls, $n=30$; CA1-NR1 KOs, $n=$ 24; CA3-NR1 KOs, $n=14$; DG-NR1 KOs, $n=18$; one-way ANOVA, $F_{(3,82)}=6.767$, $p=0.0003$; Bonferroni's post hoc test, compared with control group: CA1-NR1 KOs, $p=0.004$; CA3-NR1 KOs, $p=1.0$; DG-NR1 KOs, $p=0.163$; compared with CA1-NR1 KOs: CA3-NR1 KOs, $p=$ 0.002; DG-NR1 KOs, $p=1.0$; compared with DG-NR1 KOs: CA3-NR1 KOs, $p=$ 0.058). The attenuation of CTA memory in CA1-NR1 KOs could not be explained by differences in the taste perception, neophobic responses, or sensitivity to the US, as the CA1-NR1 KO mice, similar to CA3NR1 KOs and DG-NR1 KOs, exhibited normal responses to both taste (Fig. $1 D-G)$ and LiCl-induced suppression of locomotory behavior [gut pain; Fig. 3F; control plus NR1 KO lines $\times$ LiClinduced locomotion (10 $\mathrm{min}$ before and $10 \mathrm{~min}$ after $\mathrm{LiCl}$ injection) interaction, MANOVA, Pillai's trace, $F_{(6,44)}=2.062$, $p=0.077$; there was also no interaction between groups (control and NR1 KO lines) before $\mathrm{LiCl}$ injection, $F_{(3,22)}=2.754, p=$ 0.067 , or after $\mathrm{LiCl}$ injection, $F_{(3,22)}=1.755, p=0.185$; paired $t$ test between $10 \mathrm{~min}$ before and $10 \mathrm{~min}$ after LiCl: controls, $t_{6}=$ $29.39, p<0.0001$; CA1-NR1 KOs, $t_{6}=9.675, p<0.0001$; CA3NR1 KOs, $t_{6}=9.484, p<0.0001 ;$ DG-NR1 KOs, $t_{4}=6.537$, $p=0.003]$. Further, there were no differences in the total fluid consumption among all groups of mice; thus, this factor also cannot account for any CTA memory attenuation in the CA1NR1 KOs [control, $1.57 \pm 0.05 \mathrm{ml}$; CA1, $1.52 \pm 0.05 \mathrm{ml}$; CA3, $1.82 \pm 0.11 \mathrm{ml} ; \mathrm{DG}, 1.63 \pm 0.06 \mathrm{ml}$; there was a general interaction-one-way ANOVA, $F_{(3,82)}=2.991, p=0.036$; however, no group differed significantly from others, compared with controls $(n=30)$ : CA1-NR1 KOs $(n=24) p=1.0$, CA3-NR1 KOs $(n=14) p=0.09$, DG-NR1 KOs $(n=18) p=1.0]$.

Following the initial CTA test, the conditioned mice were reexposed to the conditioned taste daily for the next $3 \mathrm{~d}$ to study extinction of this association. Although previous studies have found accelerated CTA extinction following hippocampal damage (Yamamoto et al., 1995; Garcia-Delatorre et al., 2010), in our hands all the mutant strains exhibited extinction curves identical to the controls (Fig. 3C; mixed-model repeated-measures ANOVA: there was an interaction between tests, $F_{(3,21)}=44.071$, $p<0.0001$; however, there was no interaction between tests and genotypes, $\left.F_{(9,69)}=0.259, p=0.983\right)$. To explore this further,
B
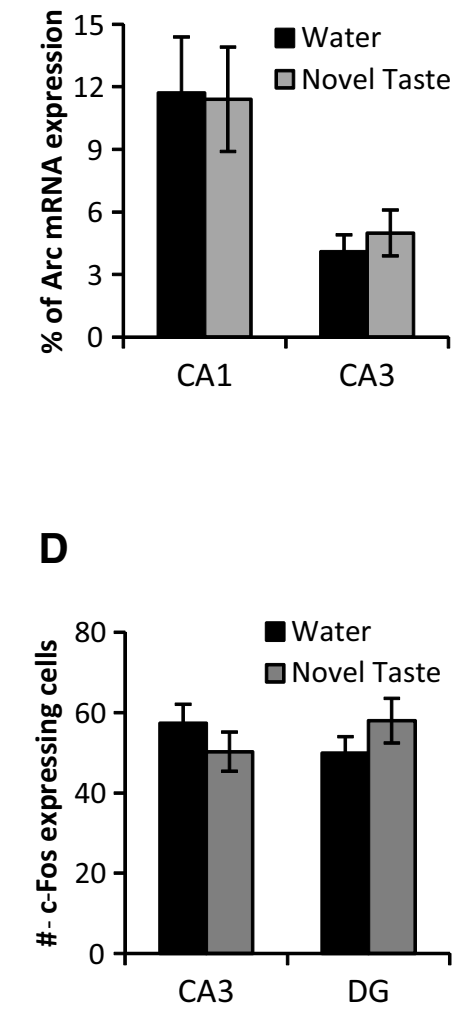

CA3
CA1

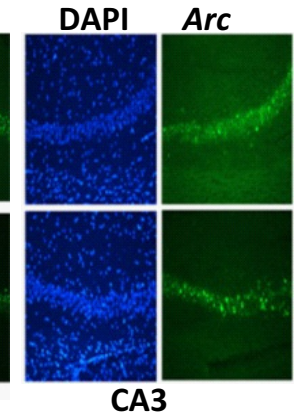

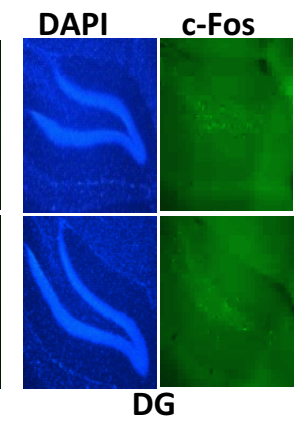

Figure 2. Incidental taste learning does not change nuclear Arc mRNA or c-fos expression in the hippocampus. $A, 0$ utline of the experiment. Three minutes after water or novel taste learning, $\mathrm{C} 57 \mathrm{BL} / 6 \mathrm{~J}$ mice were killed and $20 \mu \mathrm{m}$ brain slices were processed staining. Representative images are shown. D, Mice that received novel taste did not show significantly different c-Fos expression in CA3 or DG regions compared with water controls.

following extinction, we again presented the mice with the US $(\mathrm{LiCl})$, this time in the absence of any taste, to assess reinstatement of the initially learned association. When we analyzed the group responses, they revealed a significant effect of genotype (Fig. 3D), and further post hoc analysis revealed that the CA1NR1 KO mice again exhibited significantly less aversion to the conditioned taste than controls (one-way ANOVA, $F_{(3,26)}=$ 4.982, $p=0.008$; Dunnett's post hoc test, compared with controls: CA1-NR1 KOs, $p=0.036$; CA3-NR1 KOs, $p=0.88$; DG-NR1 KOs, $p=0.11)$. Reflecting their initial slightly lower aversion following CTA, the DG-NR1 KOs also showed less aversion, albeit not significantly lower than control mice, following reinstatement. To examine this more carefully, we compared the aversion expressed by individual mice during the last extinction test (T4 in Fig. 3C) with their aversion following reinstatement. Similar to what we observed in the group averages, the CA1-NR1 $\mathrm{KO}$ mice demonstrated no significant increase in aversion following the unpaired US, but in this analysis, neither did the DGNR1 KOs, whereas control and CA3-NR1 KO mice exhibited robust reinstatement (Fig. $3 E$; control mice, $t_{6}=-3.207, p=$ 0.018; CA1-NR1 KOs, $t_{5}=-0.155, p=0.883$; CA3-NR1 KOs, $t_{6}$ $=-5.874, p=0.001$; and DG-NR1 KOs, $t_{6}=-1.702, p=$ $0.140)$. Consistent with the idea that the CTA extinction is not unlearning (Berman and Dudai, 2001; Berman et al., 2003) our reinstatement results demonstrate that the presentation of US $7 \mathrm{~d}$ 
A

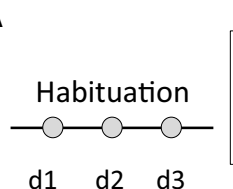
CTA conditioning

B

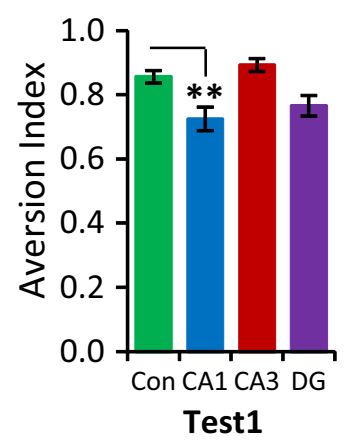

C

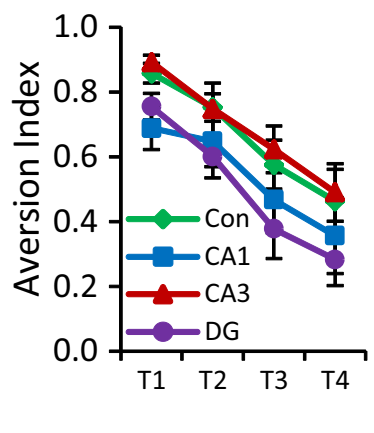

D

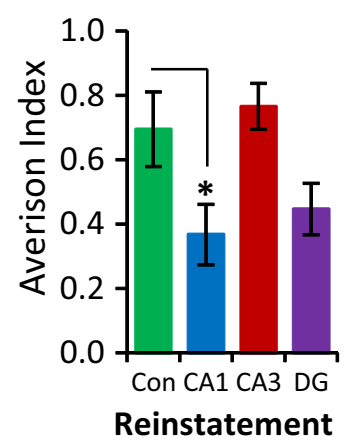

E

Test4

$\square$ Reinstatement

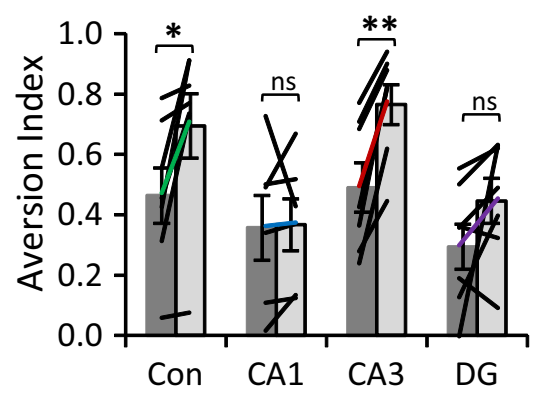

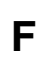

$\mathbf{F}$

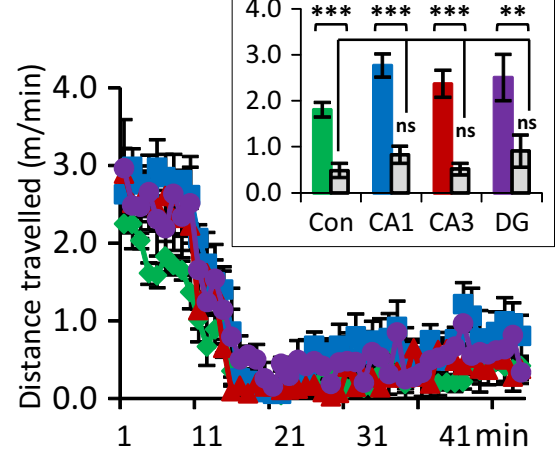

Figure 3. NMDA receptor-dependent function in CA1 is required for associative taste learning and memory formation. $\boldsymbol{A}$, Outline of the procedure used to conduct the CTA experiment. B, CA1-NR1 KOs showed an attenuation of CTA memory. DG-NR1 K0s showed a small reduction in CTA memory; however, it was not statistically different from control mice. CA3-NR1 K0s were not different from control mice. C, CA1-, CA3-, and DG-NR1 K0s exhibited normal CTA extinction. D, Reinstatement showed a main effect and CA1-NR1 KOs were statistically different from control mice. $\boldsymbol{E}$, Moreover, the paired analysis of reinstatement to that of the last extinction revealed that control mice and CA3-NR1 KOs showed clear reinstatement effect, whereas CA1-NR1 KOs and DG-NR1 KOs did not show reinstatement. $\boldsymbol{F}$, Following intraperitoneal injection of LiCl, all groups of mice showed less mobility, indicating that LiCl-elicited gut pain was processed similarly in all the NR1 KOs. Con, CA1, CA3, and DG represent control, CA1-NR1 KOs, CA3-NR1 KOs, and dentate gyrus-NR1 K0s, respectively. ns, Not significant. ${ }^{*} p<0.05,{ }^{* *} p<0.01,{ }^{* * *} p<0.001$.

after extinction leads to the robust reappearance of the aversive memory in control mice and further suggest that the loss of NMDA receptor-dependent plasticity in CA1 eliminated the original associative trace, whereas NR loss in the DG may lead to an initially weaker or more modifiable memory.

\section{Temporal modulation of CTA memory}

A critical parameter in any associative learning paradigm is the interval (ITI) or trace between the presentations of the CS and US. One interesting property of CTA is that it can be established with CS-US intervals measured in hours which, while reasonable from physiological, ecological, and evolutionary perspectives, is unique among traditional associative learning paradigms (Koh et al., 2009). In mice, both Pavlovian trace fear conditioning and trace eye-blink conditioning engage plasticity in the hippocam- pus, but with ITIs on the timescales of tens of seconds and hundreds of milliseconds, respectively (McEchron and Disterhoft, 1999; Weitemier and Ryabinin, 2004; Kitamura et al., 2014). Further, recent lesion work has suggested that CTA performed with an interval of $3 \mathrm{~h}$ between the CS and US is sensitive to hippocampal damage (Koh et al., 2009). To examine whether the requirements for hippocampal NRdependent plasticity changed with differing ITIs in the CTA paradigm, we varied the time between taste and $\mathrm{LiCl}$ injection. We subjected the two lines with quantitatively lower CTA under our standard protocol, the CA1-NR1 KOs and the DG-NR1 KOs (Fig. 3B), to "immediate CTA" in which the mice were injected with $\mathrm{LiCl}$ immediately after consuming the novel taste to assess whether (1) the lower CTA memory that was observed after regular $1 \mathrm{~h}$ ITICTA conditioning (which typically involves a $40 \mathrm{~min}$ trace between taste and malaise) was related to trace length or (2) whether CA1 is required for the tastemalaise association independent of the CS-US interval. As shown in Figure $4 A$, CA1-NR1 KOs exhibited a clear and significant attenuation of CTA memory after immediate CTA training (one-way ANOVA, $F_{(2,27)}=2.49, p<0.05$; control mice, $n=13$, Dunnett's post hoc test, compared with controls: CA1-NR1 KOs, $n=7, p=0.044$; DG-NR1 KOs, $n=8$, $p=0.679)$, suggesting that the CA1 NMDA receptors are always required for CTA, even without a trace interval. Conversely, whereas DG-NR1 KOs exhibited a trend toward impairment following regular $1 \mathrm{~h}$ ITI-CTA conditioning (Fig. 3B; $p=$ 0.142; also reflected in reinstatement, Fig. $3 D, E)$, they did not show any deficits in CTA memory following immediate CTA training. Therefore, we next subjected the DG-NR1 KOs, along with the CA3-NR1 $\mathrm{KOs}$, to CTA training with trace intervals of either 2 or $4 \mathrm{~h}$ ( $2 \mathrm{~h}$ ITI-CTA or $4 \mathrm{~h}$ ITI-CTA), to examine whether NMDA receptor in these regions is required at longer intervals. As expected, in the control, CA3-NR1, and DG-NR1 KO mice, the ability to relate the taste stimulus with bodily status ("tastevalue") weakened with increasing ITI, as demonstrated by the strong negative correlation between the ITI and memory in all three groups (Fig. 4D; controls, Pearson's $r=-0.533, p<$ 0.0001; CA3-NR1 KOs, Pearson's $r=-0.544, p=0.002$; DGNR1-KOs, Pearson's $r=-0.654, p<0.0001)$. Interestingly, compared with the controls, we observed a significant CTA memory impairment in DG-NR1 KOs when we increased the time between CS and US to 2 or $4 \mathrm{~h}$ (Fig. $4 B, C$; 2 h ITI-CTA, one-way ANOVA, $F_{(2,29)}=7.366, p=0.003$; control mice, $n=16$, Dunnett's post hoc test, compared with controls: DG-NR1 KOs, $n=8$, $p=0.012$; CA3-NR1 KOs, $n=8, p=0.342$; 4 h ITI-CTA, oneway ANOVA, $F_{(2,29)}=6.430, p=0.005$, control mice. $n=15$, 
Dunnett's post hoc test, compared with controls: DG-NR1 KOs, $n=8, p=0.012$; CA3-NR1 KOs, $n=8, p=0.648)$. These data distinguish the DG-NR1 KO mice from the CA1-NR1 KO mice, and this progressive phenotype, which becomes significant at longer trace intervals, suggests that NMDA receptor-dependent plasticity in the DG plays a critical role in the modulation of temporal context in CTA (Fig. 4D; two-way ANOVA comparing controls and DG-NR1 KOs revealed that there was a significant effect of trace interval, $F_{(3,109)}=21.097, p<0.0001$ and genotype, $F_{(1,109)}=14.967, p=0.0001$, but no significant interaction $F_{(3,109)}=$ 1.944, $p=0.113)$. Further, the actual magnitude of the difference of the mean aversion index between the control and DG-NR1 KO mice highlights the progressive nature of DG-NR1 KOs phenotype: immediate CTA, $-0.002(0.19 \%$ of the control mean), $1 \mathrm{~h}$ ITI-CTA, -0.091 ( $10.58 \%$ of the control mean), 2 h ITICTA, $-0.105(13.04 \%$ of the control mean), 4 h ITI-CTA: -0.180 (25.93\% of the control mean). Although CA3-NR1 KOs did not show any defects, they did exhibit a statistically insignificant trend toward higher aversive memory compared with control mice across all the ITICTA conditions examined (Fig. 4D). Therefore, in our last CTA experiment, we subjected CA3-NR1 KO mice to weak CTA training ( $0.05 \mathrm{M} \mathrm{LiCl}$; a weaker US) to look for enhanced CTA learning that may have been masked in our earlier experiments by the ceiling effect of strong conditioning. However, we observed no differences between mutant and control mice under this protocol (Fig. $4 E ; n=11$ mice per group, unpaired $t$ test, $t_{20}=$ $0.472, p=0.642$ ), indicating that NMDA receptor-dependent plasticity in CA3 is not required for associative CTA memory formation.

\section{Latent inhibition of CTA}

Finally, we tested whether NMDA receptor-dependent synaptic plasticity in the hippocampus is required for another form of taste memory, latent inhibition (LI; Fig. 5A). In LI, preexposure of a novel taste stimulus diminishes the efficacy of the same taste to serve as a conditioned stimulus in a subsequent associative learning trial; a positive tag of the learned taste is established and thus the weaker association leads to a weaker aversive memory formation (Fig. 5B; Rosenblum et al., 1993; Stone et al., 2005; Stern et al., 2013; CTA, $n=6$; LI, $n=8$; unpaired $t$ test, $t_{12}=$ $3.654, p=0.003)$. CA1-NR1 KOs exhibited weaker aversive memory compared with control mice in LI of CTA (Fig. $5 C$; one-way ANOVA, $F_{(3,114)}=4.210, p=0.007$; control mice, $n=$ 44; Dunnett's post hoc test, compared with controls: CA1-NR1 KOs, $n=21, p=0.009$; CA3-NR1 KOs, $n=30, p=0.891$; and DG-NR1 KOs, $n=23, p=0.9$ ). There are two possible interpre-
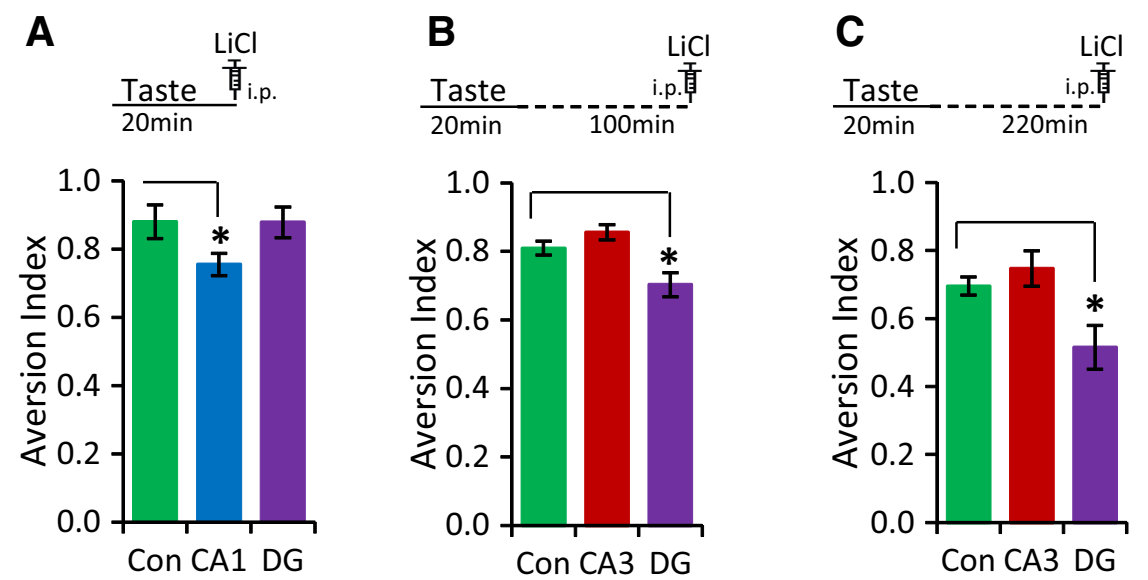

Figure 4. NMDA receptor-mediated function in DG is critical for the temporal context association in CTA learning and memory. $\boldsymbol{A}$, Top depicts the time course of immediate CTA conditioning trial. CA1-NR1 K0 s exhibited an attenuation of CTA memory, whereas the DG-NR1 KOs showed a normal CTA memory after immediate CTA training. $\boldsymbol{B}$, Top depicts the time course of the $2 \mathrm{~h}$ ITI-CTA Top depicts the time course of the $4 \mathrm{~h}$ ITI-CTA conditioning trial. DG-NR1 KOs showed impaired CTA memory in the $4 \mathrm{~h}$ ITI-CTA.

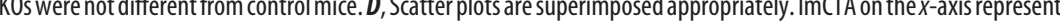
mice, CA3-NR1 K0s, and DG-NR1-K0s. In addition, the progressive nature of the phenotype of DG-NR1 KOs can be seen. $\boldsymbol{E}$, Top depicts the weak CTA conditioning trial. CA3-NR1 KOs exhibited a normal CTA memory following weak CTA training. Con, CA1, CA3, and DG represent control mice, CA1-NR1 K0s, CA3-NR1 K0s, and dentate gyrus-NR1 K0s, respectively. ${ }^{*} p<0.05$.

tations that can be made for the reduced aversive memory exhibited by CA1-NR1 KOs in LI. First, it may be due to the increased safety learning/memory regarding the taste because of the first preexposure, and hence this result can be seen as an enhanced LI in CA1-NR1 KOs. However, given that CA1-NR1 KOs clearly exhibited an attenuation of CTA memory in both immediate CTA and $1 \mathrm{~h}$ ITI-CTA training, but normal attenuation of neophobia (Fig. $1 E$ ), it is very reasonable to interpret these data as indicating that the CA1-NR1 KO line has difficulty associating a taste, be it novel (CTA) or familiar (LI), with the negative outcome.

\section{Discussion}

Conditional genetics has allowed us to address how changing the quality of hippocampal information impacts behavior, and our results demonstrate that the hippocampal circuit is involved in associative, but not incidental, taste learning. The pattern of deficits we observed across three strains of mutant mice clarifies a longstanding inconsistency and suggests that 
A

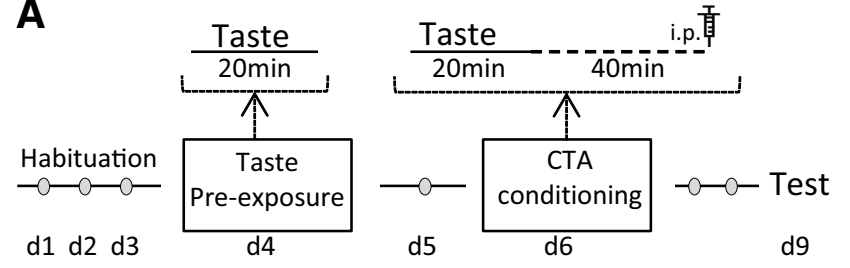

B
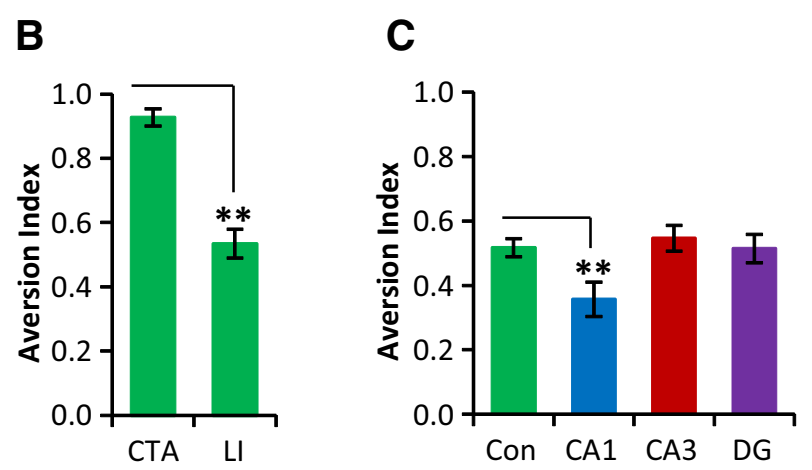

Figure 5. NMDA receptor-mediated function in CA1 is required for the positive form of the associative taste learning and memory formation. $A$, Outline of the procedure used to conduct the LI experiment. $\boldsymbol{B}$, Compared with the CTA group, the LI group (C57BL/6J) demonstrated weak aversive memory to the same sweet taste. C, CA1-NR1 K0s showed impaired LI memory, whereas CA3- and DG-NR1 KOs showed normal LI memory. Con, CA1, CA3, and DG represent control mice, CA1-NR1 K0s, CA3-NR1 KOs, and dentate gyrus-NR1 KOs, respectively. ${ }^{* *} p<0.01$.

the hippocampus may underlie an episodic component to associative taste learning.

We demonstrated that hippocampal plasticity is not involved in the sensory perception of taste and LiCl-induced pain (Figs. 1, 3 ) or in incidental taste learning (Fig. 1), but rather is engaged when learning to associate a taste and its consequence (Figs. $3 B$, $4 A-C, 5 C)$. Further, by contrasting the behavior of the CA1-NR1, CA3-NR1, and DG-NR1 KO mice, we can suggest specific circuit contributions the hippocampus may provide. In the CA1-NR1 $\mathrm{KO}$ mice, the loss of plasticity leads to unorganized hippocampal output during spatial exploration and a myriad of learning deficits (McHugh et al., 1996; Tsien et al., 1996). One possibility is that impaired CTA learning in these mice could be attributed to their contextual representational difficulties. Changes in context between CTA training and testing can attenuate memory (León et al., 2012); thus, it may be that a poor or unreliable contextual representation in the CA1-NR1 KO mice mimics this effect. Additionally, studies point to the relevance of context specificity, specifically in LI, in generating a safe or aversive taste memory trace. It has been proposed that before LI conditioning, the safe taste memory trace is enhanced with the context specificity (i.e., the more the animals spend time in their home cage, the better their safe taste memory), whereas, in contrast, the safe component of the taste is reduced with time spent in the home cage after LI conditioning (Bakner et al., 1991; De la Casa and Díaz, 2013; Molero-Chamizo, 2013). Although we conducted the LI experiment in the home cages (during preexposure, conditioning, and test), CA1-NR1 KOs exhibited increased preference to conditioned taste, suggesting that the impaired association in CA1-NR1 KOs may be attributed to the poor representation of the context.

Plasticity in the DG was necessary for learning at long (Fig. $4 B, C$ ), but not short (Fig. $4 A$ ), trace intervals, with the magni- tude of the learning deficit increasing with the length of the trace (Fig. 4D). Temporal memory has been shown to be intact in CA1-NR1 and CA3-NR1 KOs (Place et al., 2012). Although this has not been examined in the DG-NR1 KOs, these mice have previously been shown to be impaired in context discrimination, which results in the mice treating novel contexts as more familiar than do controls (McHugh et al., 2007; Wintzer et al., 2014). It is possible that increasing the ITI leads to the loss of "episodic discrimination" in DG-NR1 KOs. During habituation, these mice had experienced several similar drinking "episodes" (Fig. 3A), with the key difference being that they received water, not saccharin. On the day of conditioning, after receiving the CS, the longer trace may lead to a decrease in the novelty of the episode due to its similarity with previous experiences. This would result in a decrease in the novelty of the CS and, hence, in a weaker CTA. The reinstatement deficit we observed in these mice (Fig. $3 E$ ) suggests that despite not having a significantly lower aversion following standard CTA training, the memory formed in the DG-NR1 KOs is, in fact, altered, perhaps by these same mechanisms. The DGNR1 KOs exhibited normal LI; thus, the "safe" taste association can be formed in a manner similar to that by control mice, as this was the typical outcome of their experiences drinking water in the same manner. It may be that temporal contiguity is the major factor in longer ITI-CTA, and the defect in NR-dependent plasticity in the DG led to a decrease in the taste novelty, whereas the same NMDA receptor-dependent plasticity in the DG may not necessarily be required during the retrieval-dependent LI (which typically is $1 \mathrm{~h}$ ITI-CTA) conditioning. Although our results indicate the dispensable role of CA3-NMDA receptors in both the associative and nonassociative forms of taste learning and memory, our experiments did not test for any possible contribution of non-NMDA receptor-dependent plasticity mechanisms in CA3. For example, plasticity at the mossy fiber inputs from the DG to CA3 does not require NMDA receptors, but can strongly influence CA3 activity; it is hoped that future experiments with mice specifically lacking plasticity at these inputs can address these possibilities.

Previous studies addressing the role of the hippocampus in taste learning reported an array of conflicting phenotypes following hippocampal damage, including deficits, enhancements, and no change (Murphy and Brown, 1974; Miller et al., 1975, 1986; Bakner et al., 1991; Reilly et al., 1993; Purves et al., 1995; Yamamoto et al., 1995; Stone et al., 2005; De la Cruz et al., 2008; Ding et al., 2008; Koh et al., 2009; Garcia-Delatorre et al., 2010; Molero-Chamizo, 2013). It remains difficult to untangle these reports because of the varied conditions, species, and interventions used; various types of intervention (ranging from pharmacological blockade to permanent lesion), different target areas of the hippocampus (from unspecific to multiple subregions), and various types of training (trace intervals ranging from 0 to $30 \mathrm{~min}$ and 10 to 30 min of CS presentation) and testing (only CS-onebottle test, multiple-choice test). However, these studies share a common aim: to understand how taste learning proceeds in the absence of all or a part of hippocampal output. This is in contrast to the current work, which examines taste learning in three unique lines of mice with intact, but altered, hippocampal processing. Nonetheless, to put our data in context, we would like to attempt a succinct review of some of these earlier papers. Anisomycin, a memory consolidation blocker, microinfused into the dorsal hippocampus (male Wistar rats; coordinates: P $3.6 \mathrm{~mm}, \mathrm{~L}$ $\pm 3 \mathrm{~mm}$, V $3.3 \mathrm{~mm}$; mainly targeting but not restricted to CA1 region) during CTA conditioning did not alter CTA memory (De la Cruz et al., 2008). However, muscimol, an agonist of the 
$\mathrm{GABA}_{\mathrm{A}}$ receptor, microinfused into dorsal hippocampus (LongEvans rats; coordinates relative to bregma: AP $-3.8 \mathrm{~mm}, \mathrm{ML}$ $\pm 2.5 \mathrm{~mm}, \mathrm{DV}-1.8 \mathrm{~mm}$ from dura; mainly targeting but not essentially restricted to CA1 region), resulted in enhanced CTA memory (Stone et al., 2005). Thus, it seems that the hippocampus may not be essentially involved in the consolidation of CTA memory but, instead, its output to other parts of the gustatory circuit (muscimol essentially changes circuit properties when applied locally into the brain; Piette et al., 2012) may be vital during the CS-US association. The absence of this output may actually lead to an initially stronger associative memory. These interpretations are further supported by hippocampal lesion studies which report that regardless of the magnitude of the lesion, rats demonstrated normal CTA (taste- $\mathrm{LiCl}$ conditioning protocol; Reilly et al., 1993; Yamamoto et al., 1995); however, lesioned rats elicited accelerated CTA extinction, and this acceleration was correlated with the magnitude of the lesion in the hippocampus (dorsal or ventral hippocampus lesion did not change the CTA extinction pattern, but the whole hippocampus lesion enhanced the extinction; Yamamoto et al., 1995). These data again suggest that CTA learning can proceed in the absence of the hippocampus; however, it is qualitatively different as assessed by its ability to withstand extinction.

Despite the clear CTA phenotypes we observed in CA1-NR1 and DG-NR1 KOs, the question remains whether the hippocampus is modulating the CS-US association or actually is associated directly with the US itself. Although our data do not distinguish these possibilities, it is tempting to speculate that the episodic memory of sampling the novel taste, even in the highly familiar context of the home cage, can itself be associated with the nausea occurring minutes or hours later. The multiple memory systems theory suggests that learning engages multiple discrete memory circuits in the brain, which then can both cooperate and compete to control the behavioral outcome of an animal (White and McDonald, 2002; Wang and Morris, 2010; Packard and Goodman, 2013). In light of this, our results indicate that although the hippocampus may not be necessary for the nonassociative form of taste learning, when a taste is associated with a US, the hippocampus participates and can perhaps compete for this association. In addition, recent studies demonstrated the necessity of incorporating hippocampally encoded information into existing activated cortical frameworks in associative (schema) learning (Tse et al., 2007, 2011). Thus, it is possible that the demand for the information from CA1 to the gustatory network/circuitry is high in shorter time intervals when the novelty of the episode is strong, before it is paired with US, whereas DG-encoded information to the gustatory network/circuitry is critical for the episodic novelty to be maintained for longer durations.

In conclusion, our results shed light on both the hippocampal and classic taste learning circuits and suggest that conditional intervention in specific sublayers of hippocampus can be useful in understanding the role of hippocampus in taste learning and memory formation.

\section{References}

Bakner L, Strohen K, Nordeen M, Riccio DC (1991) Postconditioning recovery from the latent inhibition effect in conditioned taste aversion. Physiol Behav 50:1269-1272. CrossRef Medline

Ballarini F, Moncada D, Martinez MC, Alen N, Viola H (2009) Behavioral tagging is a general mechanism of long-term memory formation. Proc Natl Acad Sci U S A 106:14599-14604. CrossRef Medline

Barki-Harrington L, Elkobi A, Tzabary T, Rosenblum K (2009) Tyrosine phosphorylation of the $2 \mathrm{~B}$ subunit of the NMDA receptor is necessary for taste memory formation. J Neurosci 29:9219-9226. CrossRef Medline
Berman DE, Dudai Y (2001) Memory extinction, learning anew, and learning the new: dissociations in the molecular machinery of learning in cortex. Science 291:2417-2419. CrossRef Medline

Berman DE, Hazvi S, Stehberg J, Bahar A, Dudai Y (2003) Conflicting processes in the extinction of conditioned taste aversion: behavioral and molecular aspects of latency, apparent stagnation, and spontaneous recovery. Learn Mem 10:16-25. CrossRef Medline

De la Casa LG, Díaz E (2013) Contextual control of flavor neophobia. Physiol Behav 118:45-51. CrossRef Medline

De la Cruz V, Rodriguez-Ortiz CJ, Balderas I, Bermudez-Rattoni F (2008) Medial temporal lobe structures participate differentially in consolidation of safe and aversive taste memories. Eur J Neurosci 28:1377-1381. CrossRef Medline

Ding HK, Teixeira CM, Frankland PW (2008) Inactivation of the anterior cingulate cortex blocks expression of remote, but not recent, conditioned taste aversion memory. Learn Mem 15:290-293. CrossRef Medline

Elkobi A, Ehrlich I, Belelovsky K, Barki-Harrington L, Rosenblum K (2008) ERK-dependent PSD-95 induction in the gustatory cortex is necessary for taste learning, but not retrieval. Nat Neurosci 11:1149-1151. CrossRef Medline

Gal-Ben-Ari S, Rosenblum K (2012) Molecular mechanisms underlying memory consolidation of taste information in the cortex. Front Behav Neurosci 5:87. CrossRef Medline

Garcia-Delatorre P, Rodríguez-Ortiz CJ, Balderas I, Bermúdez-Rattoni F (2010) Differential participation of temporal structures in the consolidation and reconsolidation of taste aversion extinction. Eur J Neurosci 32: 1018-1023. CrossRef Medline

Gildish I, Manor D, David O, Sharma V, Williams D, Agarwala U, Wang X, Kenney JW, Proud CG, Rosenblum K (2012) Impaired associative taste learning and abnormal brain activation in kinase-defective eEF2K mice. Learn Mem 19:116-125. CrossRef Medline

Inberg S, Elkobi A, Edri E, Rosenblum K (2013) Taste familiarity is inversely correlated with Arc/Arg3.1 hemispheric lateralization. J Neurosci 33: 11734-11743. CrossRef Medline

Kitamura T, Pignatelli M, Suh J, Kohara K, Yoshiki A, Abe K, Tonegawa S (2014) Island cells control temporal association memory. Science 343: 896-901. CrossRef Medline

Koh MT, Bernstein IL (2005) Mapping conditioned taste aversion associations using c-fos reveals a dynamic role for insular cortex. Behav Neurosci 119:388-398. CrossRef Medline

Koh MT, Wheeler DS, Gallagher M (2009) Hippocampal lesions interfere with long-trace taste aversion conditioning. Physiol Behav 98:103-107. CrossRef Medline

León SP, Callejas-Aguilera JE, Rosas JM (2012) Context switch effects and context experience in rats' conditioned taste aversion. Psicologica Int J Methodol Exp Psychol 33:15-38.

McEchron MD, Disterhoft JF (1999) Hippocampal encoding of non-spatial trace conditioning. Hippocampus 9:385-396. CrossRef Medline

McHugh TJ, Blum KI, Tsien JZ, Tonegawa S, Wilson MA (1996) Impaired hippocampal representation of space in CA1-specific NMDAR1 knockout mice. Cell 87:1339-1349. CrossRef Medline

McHugh TJ, Jones MW, Quinn JJ, Balthasar N, Coppari R, Elmquist JK, Lowell BB, Fanselow MS, Wilson MA, Tonegawa S (2007) Dentate gyrus NMDA receptors mediate rapid pattern separation in the hippocampal network. Science 317:94-99. CrossRef Medline

Miller CR, Elkins RL, Fraser J, Peacock LJ, Hobbs SH (1975) Taste aversion and passive avoidance in rats with hippocampal lesions. Physiol Psychol 3:123-126. CrossRef

Miller JS, Nonneman AJ, Kelly KS, Neisewander JL, Isaac WL (1986) Disruption of neophobia, conditioned odor aversion, and conditioned taste aversion in rats with hippocampal lesions. Behav Neural Biol 45:240-253. CrossRef Medline

Molero-Chamizo A (2013) Excitotoxic lesion of the hippocampus of Wistar rats disrupts the circadian control of the latent inhibition of taste aversion learning. Brain Res 1533:105-113. CrossRef Medline

Murphy LR, Brown TS (1974) Hippocampal lesions and learned taste aversion. Physiol Psychol 2:60-64. CrossRef

Nakazawa K, Quirk MC, Chitwood RA, Watanabe M, Yeckel MF, Sun LD, Kato A, Carr CA, Johnston D, Wilson MA, Tonegawa S (2002) Requirement for hippocampal CA3 NMDA receptors in associative memory recall. Science 297:211-218. CrossRef Medline

Packard MG, Goodman J (2013) Factors that influence the relative use of 
multiple memory systems. Hippocampus 23:1044-1052. CrossRef Medline

Piette CE, Baez-Santiago MA, Reid EE, Katz DB, Moran A (2012) Inactivation of basolateral amygdala specifically eliminates palatability-related information in cortical sensory responses. J Neurosci 32:9981-9991. CrossRef Medline

Place R, Lykken C, Beer Z, Suh J, McHugh TJ, Tonegawa S, Eichenbaum H, Sauvage MM (2012) NMDA signaling in CAl mediates selectively the spatial component of episodic memory. Learn Mem 19:164-169. CrossRef Medline

Purves D, Bonardi C, Hall G (1995) Enhancement of latent inhibition in rats with electrolytic lesions of the hippocampus. Behav Neurosci 109:366370. CrossRef Medline

Reijmers LG, Perkins BL, Matsuo N, Mayford M (2007) Localization of a stable neural correlate of associative memory. Science 317:1230-1233. CrossRef Medline

Reilly S, Bornovalova MA (2005) Conditioned taste aversion and amygdala lesions in the rat: a critical review. Neurosci Biobehav Rev 29:1067-1088. CrossRef Medline

Reilly S, Harley C, Revusky S (1993) Ibotenate lesions of the hippocampus enhance latent inhibition in conditioned taste aversion and increase resistance to extinction in conditioned taste preference. Behav Neurosci 107:996-1004. CrossRef Medline

Rosenblum K, Meiri N, Dudai Y (1993) Taste memory: the role of protein synthesis in gustatory cortex. Behav Neural Biol 59:49-56. CrossRef Medline

Stern E, Chinnakkaruppan A, David O, Sonenberg N, Rosenblum K (2013) Blocking the eIF2alpha kinase (PKR) enhances positive and negative forms of cortex-dependent taste memory. J Neurosci 33:2517-2525. CrossRef Medline
Stone ME, Grimes BS, Katz DB (2005) Hippocampal inactivation enhances taste learning. Learn Mem 12:579-586. CrossRef Medline

Tse D, Langston RF, Kakeyama M, Bethus I, Spooner PA, Wood ER, Witter MP, Morris RG (2007) Schemas and memory consolidation. Science 316:76-82. CrossRef Medline

Tse D, Takeuchi T, Kakeyama M, Kajii Y, Okuno H, Tohyama C, Bito H, Morris RG (2011) Schema-dependent gene activation and memory encoding in neocortex. Science 333:891-895. CrossRef Medline

Tsien JZ, Huerta PT, Tonegawa S (1996) The essential role of hippocampal CA1 NMDA receptor-dependent synaptic plasticity in spatial memory. Cell 87:1327-1338. CrossRef Medline

Wang SH, Morris RG (2010) Hippocampal-neocortical interactions in memory formation, consolidation, and reconsolidation. Annu Rev Psychol 61:49-79. CrossRef Medline

Weitemier AZ, Ryabinin AE (2004) Subregion-specific differences in hippocampal activity between delay and trace fear conditioning: an immunohistochemical analysis. Brain Res 995:55-65. CrossRef Medline

White NM, McDonald RJ (2002) Multiple parallel memory systems in the brain of the rat. Neurobiol Learn Mem 77:125-184. CrossRef Medline

Wintzer ME, Boehringer R, Polygalov D, McHugh TJ (2014) The hippocampal CA2 ensemble is sensitive to contextual change. J Neurosci 34:3056-3066. CrossRef Medline

Yamamoto T, Fujimoto Y, Shimura T, Sakai N (1995) Conditioned taste aversion in rats with excitotoxic brain lesions. Neurosci Res 22:31-49. CrossRef Medline

Yefet K, Merhav M, Kuulmann-Vander S, Elkobi A, Belelovsky K, JacobsonPick S, Meiri N, Rosenblum K (2006) Different signal transduction cascades are activated simultaneously in the rat insular cortex and hippocampus following novel taste learning. Eur J Neurosci 24:14341442. CrossRef Medline 